\title{
E-governance: a global perspective
} on a new paradigm

Toshio Obi (ed)

Reviewed by

Sangeeta Gupta, Director

Information Technology and Services, TERI, New Delhi and

Gaurav Chakraverty, Associate Fellow

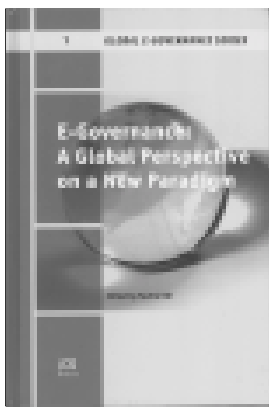

Hardbound

179 pp. 2007

ISBN 978-1-58603-776-5

Centre for IT Applications

Information Technology and Services, TERI, New Delhi

International Journal of Regulation and Governance 8(1): 97-100

E-governance is a major tool in sustainable and equitable development as it charts the vision of the world moving forward in the face of the upcoming challenges. The book E-governance: a global perspective on a new paradigm, edited by Toshio Obi, takes a good stock of the advances made in ICT (information and communication technology) in addressing the creation of information societies across countries. Over 35 authors have contributed in this volume of the global e-governance series. The book brings together presentations from various governments, business entities, and academia, who have immensely contributed to knowledge sharing of experiences and wisdom.

The five chapters of the book have maintained a good flow in explaining the need for information by different countries and the strategies of development followed by different countries. The very first chapter opens up a very interesting topic of Ubiquitous Society and showcases the decades of planning and strict implementation in countries like Japan, Korea, and Finland. The example of Japan shows how strategic planning and policy decisions on IT (information technology) are helping the country close wide gaps vis-à-vis other countries like the US, Korea, and Taiwan. It also details Japan's solution-driven approach towards pursuing a ubiquitous network paradigm. The chapter also shares with its readers Korea's dynamic initiatives and use of ICT applications to achieve high levels of standards in ICT. The topic on information issue of Finland makes for an interesting 
reading as it shows the advancements of the country towards achieving e-governance, and at the same time, showcases the challenges it faces due to its decentralized architecture. The topic elaborates on the work on e-governance, which started in the late 1950s and early 1960s, and is dedicated to the citizens of Finland, who have an unflinching trust in public administration. The chapter also covers digital local agenda, which has been taken up in various world summits as a strategy for development of the information society. The closing topic of the first chapter throws up an interesting debate on the similarity and yet the difference between e-government and e-governance.

The second chapter picks up from where the first ends, with an engrossing presentation on e-government and e-leadership, wherein establishing a vision and enabling policy synergy with other institutions require leaders who are able to communicate effectively with the policy-makers on how ICT can be an enabler in their sectors. The chapter further puts forward the new IT reform strategy of Japan and the emerging role of a CIO (Chief Information Officer), and also points towards Thailand's ICT outlook and the need for $\mathrm{R} \& \mathrm{D}$ and capacity building in this field. The latter topics go on to discuss the ICT policy and egovernment of countries like Indonesia, Philippines, Brazil, China, Finland, and Russia. The chapter also discusses the case of Taiwan, which has achieved the world's highest e-government standard. It highlights the models Taiwan is adopting and the importance of PPP (public-private partnership) model not only for Taiwan but also for other countries in future.

The six topics in the chapter on e-municipality bring forward the initiatives and strategies on local e-government and city development. Examples of strategies of Japan, China, and Estonia point towards the fact that the local government holds huge amount of data on the residents, and that all efforts should be made to ensure the trust and safety of the residents as the e-local government initiative progresses. The presentation on the city of San Fernando provides an interesting reading on how the city realized the need for ICT, and how good planning and use of PPP have resulted in good and transparent governance. Open city portal focuses on empowering the citizens with local content through creation of citizen-centric information portals.

The fourth chapter discusses several important topics on ICT and applications. It discusses the new-generation technologies in broadband for development of an informed society. The chapter 
covers very important discussion on disaster reduction by profiling the views of UNESCO and strategies for disaster reduction. The chapter discusses the major role that ICT can play in coping with natural hazards and also touches upon the emerging issues like environmental degradation and global warming. Disaster can affect everyone; having a good framework for action could reduce the impacts drastically. This has been supported with the example of tsunami wherein failure of early warning system, risk assessment, disaster preparedness, and communication resulted in large-scale devastation. The chapter also covers very interesting topics on e-projects in Finland and Thailand's e-filing strategy. The role of universities in e-governance has been well highlighted in the chapter as they can support the e-governance activities in a collaborative effort between public and private sector institutions. They can also play a role in research, consultancy, training, and information dissemination so that everybody benefits from this initiative. E-governance would not be complete without reaching the last mile; use of smart cards has been debated as an option with several countries adopting them. E-governance is a major tool towards good governance, bringing the administration closer to its citizens, and reducing time and space challenges that we face today. The book also captures the Georgian experience that includes various initiatives by the government on ICT incubators that would form a good base for development in the future. The chapter also brings out a very good presentation on various models using broadband infrastructure for local and regional governments with relevant cityspecific examples. The chapter brings forth the need for quality manpower in future and underlines the huge scope education can offer in equipping future managers, experts, CIOs, and so on with knowledge in using ICT as a tool for development.

The final chapter of the book covers the very contemporary subject of manpower in the field of ICT. With rapid progress in technology and creation of informed societies, there is a widespread need for quality manpower, which would bridge the gap between the people and technology. The role of CIO in today's world has been rightly put forward in this chapter. Citing examples of countries like Japan, Thailand, the US, and Europe, the importance of the CIO in both the public and private sectors has been brought out in the book.

The book is a good repository of knowledge on the present and future trends of e-governance, with rich contributions from 
experts from all across the globe. It brings forth different perspectives that countries take as they tread the path of socioeconomic development and creation of Ubiquitous Society. The book also showcases the power of ICT and how various models work in synergy to achieve good governance. Overall, this book is a must read for policy-makers and researchers. 